\title{
IMPLICACIONES ÉTICAS Y JURÍDICAS DE LA MATERNIDAD SUBROGADA. APROXIMACIÓN A UNA VISIÓN EUROPEA
}

\begin{abstract}
Aitziber Emaldi Cirión ${ }^{1}$
Resumen: Los avances biotecnológicos son abrumadores y la realidad social cambia con ellos. En efecto, la nueva ley en España sobre los matrimonios homosexuales ha propiciado que parejas de mujeres y de hombres que se casan puedan procrear no solo mediante la adopción, sino también por la fecundación in vitro. Así, la gestación por sustitución se está convirtiendo en la vía preferente para que parejas heterosexuales u homosexuales con problemas específicos, parejas de hombres y para el varón sin pareja puedan tener descendencia. Esta situación crea múltiples conflictos éticos y jurídicos difíciles de resolver: filiación del menor, mercantilización de la mujer, instrumentalización y compraventa de niños, etc. En este artículo se analizarán los aspectos bioéticos en conflicto, sin olvidar la regulación jurídica que existe al respecto.
\end{abstract}

Palabras clave: técnicas de reproducción asistida, gestación por sustitución, filiación, contratos, legislación, jurisprudencia europea

\section{Ethical and juridical implications relating to surrogate pregnancy. An overview from a european perspective}

\begin{abstract}
We find ourselves in a time of far reaching biotechnological breakthroughs and alongside with this, society is also experiencing changes. In this sense, new regulations regarding homosexual marriage have opened an scenario where same sex couples of men or women, may "procreate", not only by means of adoption - not permitted for homosexual couples in many countries - but also through in vitro fertilization. For this reason, surrogate pregnancy is becoming the option of choice enabling heterosexual couples with specific problems, male couples, and males without a female partner to have a child. Indeed, as surrogate pregnancy techniques proliferates, ethical conflicts arise: the possibility of men to have their own children, problems relating filiation, instrumentalization of women and babies, legal solutions given by different European countries. In this article, both bioethical and legal issues regarding surrogate pregnancy will be analyse looking for the best interest of the minors.
\end{abstract}

Key words: assisted reproductive techniques, surrogate pregnancy, filiation, European legislation, European Case Law Notes

\section{Implicaçóes éticas e jurídicas da maternidade por substituiçáo. Aproximaçáo de uma visáo europeia}

Resumo: Os avanços biotecnológicos são avassaladores e a realidade social se transforma com eles. Com efeito, a nova lei espanhola sobre o casamento homossexual tem propiciado que casais de mulheres e de homens que se casam possam procriar não só através da adoção, mas também por fertilização in vitro. Assim, a gestação por substituição está se tornando a alternativa preferida para que casais heterossexuais ou homossexuais com problemas específicos, casais de homens e homens solteiros possam ter filhos. Esta situação cria vários conflitos éticos e jurídicos que são difíceis de resolver: filiação da criança, mercantilização da mulher, instrumentalização e compra e venda de crianças, etc. Este artigo irá analisar os aspectos bioéticos, sem esquecer a regulação jurídica a este respeito.

Palavras-chave: técnicas de reprodução assistida, gestação por substituição, filiação, contratos, legislação e jurisprudência europeia

\footnotetext{
${ }^{1}$ Comité de Ética de Investigación, Universidad de Deusto, Bilbao, España

Correspondencia: aitziber.emaldi@deusto.es
} 


\section{Situación actual}

La realidad social está teniendo múltiples cambios(1) y la regulación en España sobre los matrimonios homosexuales ha propiciado que parejas de mujeres y de hombres que se casan, puedan procrear, no solo mediante la adopción —no permitida para parejas del mismo sexo en muchos países-, sino también por fecundación in vitro(2). Así, la gestación por sustitución se está convirtiendo en la vía preferente para que parejas heterosexuales u homosexuales con problemas específicos, parejas de hombres y para el varón sin pareja puedan tener descendencia. El problema que estudiaremos es que, en España, esta técnica no se puede llevar a cabo porque el contrato de gestación por sustitución es nulo de pleno derecho(3) y, sin embargo, hay parejas que acuden a otros países para llevarla a cabo y, posteriormente, quieren que el Registro Civil español les reconozca como padres de la criatura.

\section{La gestación por sustitución en España}

De acuerdo con la normativa española(4) cuando regula este tipo de contrato, destacamos que la Ley española 14/2006, de técnicas de reproducción humana asistida, es clara cuando, en su artículo 10.1, declara nulo de pleno derecho el contrato por el que se convenga la gestación, con o sin precio, a cargo de una mujer que renuncia a la filiación materna a favor del contratante o de un tercero. Esto es, la maternidad queda determinada por el parto, por tanto, la madre gestante - que aportara o no gametos - sería la madre del recién nacido para efectos civiles. Por otra parte, el Convenio de Biomedicina(5) recoge en su artículo 21 que "El cuerpo humano y sus partes como tales no deben ser objeto de lucro", por lo que se podría entender que el útero de una mujer no puede ser alquilado.

Por su parte, el Código Civil español otorga a estos contratos un carácter de nulidad, en primer lugar por carecer éstos de objeto. De hecho, se violaría el art. 1.261 CC, en el que se recoge que no existe un contrato sino cuando concurran los requisitos de: objeto cierto que sea materia del contrato. Este principio enlaza con el establecido en el art. 1.271, en que se dice que pueden ser objeto de contrato todas las cosas que no están fuera del comercio de los hombres. En segundo lugar, sería nulo el contrato por ser un "contrato sin causa, o con causa ilícita", puesto que la causa de este contrato se opondría a las leyes y la moral (1.275 CC), y siguiendo con las argumentaciones precedentes, los artículos 1305 y 1306 del Código civil español disponen que cuando la nulidad provenga de ser ilícita la causa u objeto del contrato, si el hecho constituye un delito o falta común a ambos contratantes, carecerán de acción entre sí, y se procederá contra ellos, dándose, además, a las cosas o precio que hubiesen sido materia de contrato. Por consiguiente, si se parte de la nulidad de tal acuerdo, se niega acción a la mujer gestante para poder reclamar a la otra lo que ésta le prometió; tampoco podrá reclamarse a la gestante lo que se le entregó como retribución, aun en el supuesto de arrepentimiento. Así pues, como el negocio jurídico es nulo, no se derivan obligaciones para las partes.

\section{Problemas en el Registro Civil tras realizar la gestación por sustitución}

Está claro que en España el contrato de gestación por sustitución es nulo de pleno derecho; sin embargo, muchos ciudadanos acuden a países en que se permite esta técnica y luego traen a la criatura para ser inscrita en el Registro Civil espańol, generando muchos problemas(6).

Ante esta situación, nos encontramos con un problema jurídico de gran relevancia y por ello es necesario estudiar varios preceptos legales. En primer lugar, la Ley espańola 14/2006 sobre técnicas de reproducción humana asistida, que reconoce distintas técnicas para hacer frente a la infertilidad (art. 2.1) y es contundente cuando sanciona con la nulidad de pleno derecho aquel contrato por el cual se convenga la gestación, con o sin precio, de una mujer, la cual renunciaría posteriormente a la filiación materna a favor del contratante o de un tercero (art. 10.1). Sin embargo, el legislador contempla la posibilidad de que se pueda producir tal situación y, por ello, concreta —igual que el Código Civil— que dicha filiación será determinada por el parto. Esta misma ley estipula que queda a salvo la posible acción de reclamación de la paternidad respecto del padre biológico — si aportó el material reproductor-, conforme a las reglas generales (art. 10.3). 
En segundo lugar, la Ley 13/2005, de 1 de julio, por la que se modifica el Código Civil español en materia de derecho a contraer matrimonio, que permite ejercer dicho derecho a dos personas del mismo sexo, lo que conlleva a que se le reconozcan otros derechos, como puede ser el derecho a fundar una familia, o el derecho a procrear(7), que puede tener consideración de derecho subjetivo.

A continuación, de manera cronológica, para apreciar la evolución de las soluciones dadas a esta situación y teniendo siempre presentes los preceptos mencionados en los párrafos anteriores, estudiaremos cómo se resuelven los supuestos de gestación por sustitución en España.

\section{- Dirección General de los Registros y del Notariado de 2009}

Para dar respuesta a estos supuestos de gestación por sustitución, la Dirección General de los Registros y del Notariado dictó una resolución el 18 de febrero de 2009 (RJ 2009\1735)(8) en la que admitió la inscripción de dos niños nacidos en California mediante gestación por sustitución, siendo el solicitante de la inscripción quien aportó el gameto masculino(9). Esta resolución revisa el procedimiento del documento extranjero por el que reconocía la filiación de los niños a favor de una pareja española comitente y dictamina que ha de permitirse el acceso al Registro Civil consular de la misma y proceder a autorizar su práctica del asiento registral(10). Para ello, el encargado del Registro debe controlar la legalidad de la certificación registral extranjera y comprobar que la misma dimana de una autoridad y que no es contraria al orden público internacional español. Todo este procedimiento responde o tiene su base en el artículo 81: "el documento auténtico, sea original o testimonio, sea judicial, administrativo o notarial, es título para inscribir el hecho de que da fe. También lo es el documento auténtico extranjero, con fuerza en Espańa con arreglo a las leyes o a los Tratados internacionales", y en el artículo 85: "para practicar inscripciones sin expediente en virtud de certificación de Registro extranjero se requiere que este sea regular y auténtico, de modo que el asiento de que se certifica, en cuanto a los hechos de que da fe, tenga garantías análogas a las exigidas para la inscripción por la Ley española.
La falta de inscripción en el Registro extranjero no impide practicarla en el español mediante título suficiente" del Decreto de 14 de noviembre de 1958, por el que se aprueba el Reglamento de Registro Civil(11).

Se argumenta en dicha resolución que no permitir la inscripción registral de los nacidos por parte de dos varones sería discriminatorio por razón de sexo y, por tanto, contario a la Constitución española (art. 14), al permitir en la Ley de técnicas de reproducción asistida la inscripción de la filiación a favor de mujeres, resultante de la aplicación de técnicas de reproducción asistida (art. 7.3). En conclusión, el interés superior del menor aconseja que se inscriba en España la filiación que figura en el Registro extranjero. No obstante, esta resolución fue impugnada por el Ministerio Fiscal, dando lugar a la Sentencia del Juzgado de $1^{\text {a }}$ Instancia número 15 de Valencia, de 15 de septiembre de 2010, la cual anula la inscripción registral, al considerar que se ha acudido a una vía errónea para la inscripción de los menores, ya que debería haberse comprobado la realidad del hecho inscrito y su ilegalidad conforme a la Ley de técnicas de reproducción asistida (art.10), por tanto, considera que debe rechazarse su inscripción registral. Dicha sentencia fue confirmada por la Audiencia Provincial de Valencia de 23 de noviembre de 2011.

\section{Instrucción de la Dirección General de los Re- gistros y del Notariado de 2010}

La resolución de 2009 había intentado dar respuesta a un caso, pero no había solucionado la cuestión de fondo de la maternidad subrogada llevada a cabo por ciudadanos españoles que acuden al extranjero para gestar un hijo con un vientre de alquiler $y$, posteriormente, pretenden la inscripción del recién nacido en el Registro Civil español mediante la técnica del reconocimiento internacional de resoluciones judiciales. Por ello, con la intención de regular el procedimiento de inscripción de los nacidos mediando un contrato de maternidad subrogada y con la idea de a sentar un criterio para aplicarse en los registros consulares al respecto, se dicta esta Instrucción de la Dirección General de los Registros y del Notariado de 5 de octubre de 2010(12). 
Mediante esta instrucción, se permite la inscripción en el Registro Civil español del nacimiento del menor, siempre que exista una resolución judicial extranjera que avale la legalidad del nacimiento conforme al derecho vigente en ese país(12). Además, en esta Instrucción se exigirá, a partir de ese momento, no solo una certificación registral extranjera acompañada de certificación médica relativa al nacimiento del menor en la que no conste la identidad de la madre gestante - como ocurrió en el caso citado- , sino que se exige una resolución judicial extrajera en la que conste la renuncia, por parte de la madre gestante, de sus derechos. Además, "se deberá comprobar que no se ha producido una vulneración especial del interés superior del menor y de los derechos de la madre gestante”, es decir, esta deberá haber renunciado a su maternidad de manera capaz, libre y voluntaria, sin incurrir en error, dolo o violencia(13).

Cabe objetar a este respecto que, sin aplicar el artículo 10 de la Ley de reproducción asistida que considera estos contratos nulos de pleno derecho- - y evitando la aplicación de la Ley 54/2007 de Adopción Internacional, se podría pensar en la posible existencia de un fraude de ley(14), sancionado por el art. 6.4 del Código Civil, al estipular que "los actos realizados al amparo del texto de una norma que persigan un resultado prohibido por el ordenamiento jurídico, o contario a él, se considerarán ejecutados en fraude de ley y no impedirán la debida aplicación de la norma que hubiere tratado de eludir".

En definitiva, con esta Instrucción, que parte del principio del interés superior del menor, se vuelve a dar respuesta a un caso puntual, incluso en perjuicio de la seguridad jurídica, pero no regula de manera general la maternidad subrogada, que es lo que se esperaba de esta Instrucción.

\section{Audiencia Provincial de Valencia de 2011}

La Audiencia Provincial de Valencia de 23 de noviembre de 2011 rechaza la inscripción por vulnerar el artículo 23 de la Ley del Registro Civil de 1957, en el que se dice que sólo se puede inscribir la filiación mediante certificación extendida en Registro extranjero "siempre que no haya duda de la realidad del hecho inscrito y de su legalidad conforme a la Ley española" lo cual, eviden- temente, no se cumple por contrariar el artículo 10 de la Ley de técnicas de reproducción asistida que considera nulo de pleno derecho el contrato de subrogación materna.

Además, la Audiencia considera que la solicitud de inscripción no se ajusta al control de legalidad derivado del art. 23 de la Ley del Registro Civil y advierte que la satisfacción del interés del menor "no puede conseguirse infringiendo la ley, máxime cuando la propia ley ofrece cauces para la inscripción de la filiación de los menores a favor de los demandados -reclamación de la determinación de la filiación a favor del varón donante del gameto (art. 10.3 Ley de técnicas de reproducción asistida) y posterior adopción por parte de su pareja (art. 175 del Código Civil).

\section{Sentencia del Tribunal Supremo de 6 de febre- ro de 2014}

El problema de la maternidad subrogada llega al Tribunal Supremo español a consecuencia del recurso interpuesto contra la sentencia de la $\mathrm{Au}$ diencia Provincial de Valencia de 2011 por parte de la pareja cuya inscripción fue denegada. El Tribunal Supremo resolvió este recurso mediante sentencia de 6 de febrero de 2014(15), no sin tener críticas (16), por considerar que no se armonizan los criterios jurisprudenciales y administrativos existentes sobre esta cuestión para favorecer la seguridad jurídica.

El Tribunal Supremo consideró que para reconocer la certificación extranjera en la que conste la filiación se debe exigir que se lleve un control especial, verificando que la misma sea auténtica, de manera que el asiento registral que certifica otorgue garantías similares a las exigidas para la inscripción en España. No obstante, la Ley del Registro Civil de 1957 (art. 23) exige que se efectúe un control también de las cuestiones de fondo, esto es, respetando la legislación española y el "orden público internacional español". El tribunal entendía que este último estaría formado por todas las normas que regulan aspectos fundamentales de la familia y de las relaciones paternofiliales. Por tanto, en este caso se considera que la decisión de la autoridad registral de atribuir la condición de padres a la pareja que contrató la gestación por sustitución es contraria al orden pú- 
blico internacional espańol, por ser incompatible con las normas que regulan las relaciones familiares, en concreto con el artículo 10.1. de la Ley de técnicas de reproducción asistida, el cual forma parte del orden público, ya que dicho artículo trata de evitar que los avances en estas técnicas vulneren la dignidad de la mujer gestante y del niño, mercantilizando la gestación y la filiación, cosificando a la mujer gestante y al niño y permitiendo a determinados intermediarios realizar negocio con ellos.

Por estas razones, el Tribunal Supremo deniega la trascripción al Registro Civil de las actas extranjeras de nacimiento que establecen la filiación de los niños respecto de los sujetos comitentes en este tipo de contratos, por ser contarios al orden público internacional español.

Además, el Tribunal Supremo recomienda la posibilidad de buscar, por el bien del menor, algún vínculo familiar entre este y los comitentes. Por ello, y de acuerdo con el artículo 10.3 de la Ley de técnicas de reproducción asistida, se permite la reclamación de la paternidad respecto del padre biológico, conforme a las reglas generales, por lo que si alguno de los recurrentes lo fuera - por aportar sus gametos o el embrión a la mujer gestante-, podría determinarse la filiación paterna o materna y, paralelamente, se podría completar la integración del menor en la familia mediante el acogimiento familiar o la adopción que permiten la formalización jurídica de la integración real de los menores en tal núcleo familiar. En el supuesto de que los recurrentes no hubieran aportado sus gametos, en tal caso deberían acudir a la Ley 54/2007 de Adopción Internacional, de 28 de diciembre.

Asimismo, admite la posibilidad de que los menores adquieran la nacionalidad, una vez que estuviere determinada la filiación biológica respecto del padre biológico y la filiación por criterios no biológicos respecto del otro miembro de la pareja, mediante la adopción.

Tras un exhaustivo estudio, considero que esta sentencia fue apropiada, ya que cautela el interés superior del menor, siguiendo la línea que, $a$ posteriori, marcará el Tribunal Europeo de Derechos Humanos. Se trata de aplicar la legislación española — por ello no permite su inscripción-, pero dando soluciones para que los hijos se puedan vincular a esa familia "de facto" de una u otra manera. En efecto, no se puede consentir la vulneración del artículo 10 de la Ley de TRA, pero tampoco desproteger a unos menores y dejarlos en un limbo jurídico. Sin embargo, aun cuando se ha dado esta solución satisfactoria para las partes, ha de ser prioritario un cambio legislativo que regule esta práctica para que se ofrezca una seguridad jurídica a todos los sujetos implicados.

\section{Ley del Registro Civil Español de 2011 que en- tra en vigor en España en 2014}

En 2011 se aprueba, en España, la Ley 20/2011, de 21 de julio, del Registro Civil, que entra en vigor en 2014. En esta se recoge, en sus artículos 97 y 98 , el procedimiento que se debe seguir para el reconocimiento de asientos registrales extranjeros, exigiendo los siguientes controles:

A) Cuando se trate de un documento público extranjero no judicial, se estipula que será título para inscribir el hecho o acto de que da fe siempre que cumpla los siguientes requisitos: $10^{\circ}$ Que el documento ha sido otorgado por autoridad extranjera competente conforme a la legislación de su Estado; 2. ${ }^{\circ}$ Que la autoridad extranjera haya intervenido en la confección del documento desarrollando funciones equivalentes a las que desempeñan las autoridades españolas en la materia de que se trate; 3. ${ }^{\circ}$ Que el hecho o acto contenido en el documento sea válido conforme al ordenamiento designado por las normas españolas de Derecho internacional privado; y 4. ${ }^{\circ}$ Que la inscripción del documento extranjero no resulte manifiestamente incompatible con el orden público español.

B) Si se trata de una certificación de asientos extendidos en Registros extranjeros, estos serán título para la inscripción en el Registro Civil español siempre que se verifiquen los siguientes requisitos: 1) Que la certificación ha sido expedida por autoridad extranjera competente conforme a la legislación de su Estado; 2) Que el Registro extranjero de procedencia tenga, en cuanto a los hechos de que da fe, análogas garantías a las exigidas para la inscripción por la ley española; 3) Que el hecho o acto contenido en la certificación registral 
extranjera sea válido conforme al ordenamiento designado por las normas españolas de Derecho internacional privado; 4) Que la inscripción de la certificación registral extranjera no resulta manifiestamente incompatible con el orden público español. Además, se estipula que, en el caso de que la certificación constituya mero reflejo registral de una resolución judicial previa, será esta el título que tenga acceso al Registro. Con tal fin deberá reconocerse la resolución judicial de acuerdo a alguno de los procedimientos contemplados en el artículo 96, donde se prevén dos procedimientos: acudir a la vía judicial instando el exequátur de la resolución extranjera, o bien mediante un procedimiento ante el Registro Civil. Finalmente, se exige que se completen por los medios legales o convencionales oportunos los datos y circunstancias que no puedan obtenerse directamente de la certificación extranjera, por no contenerlos o por defectos formales que afecten a la autenticidad o a la realidad de los hechos que incorporan.

En conclusión, a la vista de este precepto legal, seguimos teniendo división doctrinal, porque hay autores(17) que consideran que la decisión judicial debería ser la misma: el rechazo a la maternidad subrogada, respetando así la Ley de TRA (art. $10)$, ya que dicho precepto pertenece al orden público español, en contra de lo manifestado por la DGRN en 2009 —que defendía la inscripción porque no permitir que la filiación de los nacidos conste a favor de dos varones resultaría discriminatorio por razón de sexo, lo que está radicalmente prohibido por el artículo 14 de la Constitución Española-. Por consiguiente, en opinión de estos autores, ni se puede aceptar la institución en sí ni permitir ciertos efectos de la misma. Sin embargo, también ha de tenerse en cuenta los principios del interés superior del menor aludido por el Tribunal Supremo y el principio de la continuidad de las relaciones familiares, mencionado por el TEDH.

\section{Resoluciones del Tribunal Europeo de Dere- chos Humanos de 2014 y 2015}

Estos supuestos de gestación por sustitución han llegado, con el tiempo, al Tribunal Europeo de Derechos Humanos (TEDH), por lo que analizaremos las sentencias más recientes al respecto: dos de ellas de 2014 contra el Estado francés y otra de

\section{5 contra el Estado italiano.}

En primer lugar, tenemos dos resoluciones, ambas del día 26 de junio de 2014, que tienen el mismo demandante: el Estado francés (asuntos: Mennesson c. Francia y Labasee c. Francia). En estos supuestos, se trata de dos matrimonios franceses que contrataron en EEUU sendas gestaciones por sustitución —no permitidas en la legislación francesa- De dichas gestaciones nacieron, en un caso, dos niñas gemelas y, en el otro, una niña. En ambos supuestos, el Tribunal de Casación francés manifestó que "en presencia de este fraude, ni el interés superior del niño garantizado por el art. 3 del Convenio sobre los Derechos del niño, ni el respeto a la vida privada y familiar, en el sentido del art. 8 del Convenio Europeo de Derechos Humanos de 1950, podían ser invocados útilmente”. En definitiva, el Tribunal de Casación francés manifiesta, de manera poco acertada, si se pensara en el interés del menor, los siguientes aspectos: la denegación de la transcripción al Registro Civil de las actas extranjeras de nacimiento que establecen la filiación de las nińas respecto de los padres comitentes en supuestos de contratos de maternidad subrogada; la imposibilidad de que pueda determinarse legalmente en Francia cualquier relación de filiación entre las niñas y los padres comitentes; incluso, anula el posible reconocimiento de la paternidad del padre biológico, debido al carácter fraudulento del contrato de gestación por sustitución. Además, proclama la imposibilidad de que las niñas puedan adquirir la nacionalidad francesa y de que puedan heredar a los comitentes en calidad de hijas.

En ambos casos, el Tribunal Europeo de Derechos Humanos hace su argumentación en atención a la aplicación del Convenio de 1950 y considera que el Estado francés, al denegar la filiación, ha lesionado el derecho de los menores al respeto de su vida privada, ya que, al valorar entre los intereses del Estado y los de los padres recurrentes, no ha tenido en cuenta el principio del interés del menor, lo que provoca una lesión del artículo 8 del Convenio, con la consiguiente condena al Estado francés. Se trataría de aplicar un criterio del "principio de continuidad" en las relaciones familiares, que previamente había reconocido el propio Tribunal en anteriores resoluciones (Asunto: S.H. y otros v. Austria de 2001 (JUR 2001/3.69437). 
En segundo lugar, este mismo tribunal ha dictado otra resolución el 27 de enero de 2015 (Affaire Pardiso et Campanelli c. Itailie - Application no. 25358/12) y en la misma línea que la argumentada en los supuestos precedentes. En este caso, los recurrentes, un matrimonio de italianos, acudieron a Rusia para llevar a cabo un contrato de gestación por sustitución. Una vez nacido en 2011, y de acuerdo con la ley rusa, los comitentes fueron inscritos como padres del menor sin indicar que el mismo había nacido como resultado de un contrato de maternidad subrogada. Cuando llegaron a Italia y quisieron inscribir al menor, las autoridades italianas se negaron a hacerlo, alegando que el consulado de Moscú había comunicado que la documentación tenía información falsa; además, consideraron que la inscripción sería contraria al orden público, ya que en Italia no se permite esta práctica; y finalmente resultó que, tras realizar un test de $\mathrm{ADN}$, se reveló que el padre comitente no era padre biológico del hijo. A la vista de estos hechos, las autoridades italianas quitaron a los padres comitentes la custodia del hijo y lo entregaron a un centro estatal. De hecho, en 2013, el menor recibió una nueva identidad mediante un nuevo certificado de nacimiento en el que se estipulaba que el menor era hijo de padres desconocidos.

Ante este supuesto, el Tribunal Europeo declara que existe una clara vulneración del artículo $8 \mathrm{del}$ Convenio, en cuanto les quitan la custodia y hacen entrega del menor a las autoridades italianas, lo que es inadmisible porque existía una vida familiar "de facto", aunque fuera de seis meses; que se da primacía al respeto de la ley italiana y para ello se realiza un balance entre el interés público y el interés de respetar la vida privada de los sujetos recurrentes, ganando el primero, sin embargo, no se atiende al interés superior del menor; y finalmente, el Tribunal considera que quitar la custodia a los sujetos recurrentes sobre la base de que aquellos han ido contra la ley italiana es una medida extrema que solo se debería dar en el caso de que el menor estuviera en peligro, algo que no sucede en este supuesto.

Desde mi punto de vista, el Estado francés y el Estado Italiano no miran por el interés superior del menor, que es lo más importante en estos supuestos, sino que lo que pretenden es castigar el comportamiento de los padres comitentes, dejando violentados, en consecuencia, muchos derechos de los menores: nacionalidad, herencia, custodia... jno es ético dejar en el limbo jurídico y lesionar derechos de unos menores por querer dar un castigo ejemplar a los ciudadanos de un país! Lo que se debería hacer es dar una solución con la que se proteja el interés superior del menor y, paralelamente, se elabore una legislación más estricta sobre esta práctica, aceptándola o considerándola un delito, pero ofreciendo seguridad jurídica a todos los sujetos implicados.

\section{Tribunal Supremo Español: Auto de 2 de febre- ro de 2015}

Continuando con el orden cronológico de esta investigación y como ya indiqué, en España los recurrentes en casación promovieron un incidente de nulidad de actuaciones contra la sentencia dictada el 6 de febrero de 2014, por considerar que la misma vulneraba los siguientes derechos fundamentales de aquellos: a) el derecho a la tutela judicial efectiva, puesto que la Sala habría infringido las normas sobre prueba y carga de la prueba, a partir de la existencia de unos hechos cuya existencia no está probada, y habría desviado el debate desde una cuestión registral civil a otra distinta sobre las consecuencias de la ilicitud en España de la gestación por sustitución; b) el derecho a la igualdad sin discriminación, tanto de los menores —en cuanto a la no discriminación por razón de nacimiento- como de los padres en cuanto a la no discriminación por razón de su orientación sexual-; c) el derecho a la intimidad familiar — en cuanto al derecho de la pareja a la procreación médica asistida.

Este recurso ha sido resuelto por la Sala de lo Civil del Tribunal Supremo en el Auto de 2 de febrero de 2015, el cual, por su parte, tiene también un voto particular. La Sala expone acertadamente las razones por las cuales la sentencia no vulnera los derechos invocados por los recurrentes y esta conclusión resulta confirmada a la vista de las sentencias del TEDH (casos Labassee y Mennesson), donde el TEDH si detectó una violación de los derechos de los menores. Por tanto, la Sala considera que "No ha lugar a declarar la nulidad de la sentencia núm. 835/2013, de 6 de febrero de 2014, dictada por el Pleno de esta Sala...". 


\section{Conclusiones}

Primera: se debería regular algunos requisitos si se decidiera permitir esta práctica, entre otros mencionaremos: a) que la madre gestante no tuviera una ventaja económica, aun así el Estado debería estipular las tarifas para que la cantidad entregada sea en concepto de una compensación y no de una compraventa encubierta; b) que la mujer de la pareja no fuera apta para asumir la gestación; c) que la pareja comitente aportase bien el embrión, el esperma o el óvulo; d) que la mujer gestante cumpliera una serie de requisitos: edad, salud psicofísica, etc.; e) veces que una mujer puede prestarse a la gestación por sustitución; f) soluciones en caso de incumplimiento contractual, en el supuesto de que la madre de sustitución no quisiera entregar el hijo(18).

Segunda: se debería regular qué ocurriría si durante el embarazo se llevaran a cabo diagnósticos genéticos prenatales que detectaran una anomalía fetal y la pareja beneficiaria quisiera interrumpir el embarazo, no así la mujer portadora del embrión.

Tercera: si durante el trascurso de la gestación se produjera la separación de la pareja o bien su muerte, sería una situación que necesitaría estar regulada previamente. En este caso, no se podría obligar a que la madre sustituta se lo quedase o lo entregase en adopción, sino que tendría que responder la pareja beneficiaria que se ha separado y, en el supuesto de muerte, debería seguirse los mismos procedimientos que se siguen para los hijos póstumos.

Cuarta: la posibilidad de que pueda producirse un embarazo múltiple es una cuestión que debería estar recogida en el contrato o en la ley. En estos supuestos, se podría tratar de forzar a la madre gestante a que procediese a interrumpir el embarazo de uno de los embriones, en la medida en que el acuerdo o contrato únicamente contemple la gestación de uno de ellos y no de los dos. Otra opción sería estipular que la pareja comitente se hiciera cargo de todos los hijos nacidos durante este proceso.

Quinta: la posibilidad de que, tras la maternidad subrogada, la pareja beneficiaria pudiera disfru- tar o no del permiso de maternidad y paternidad previsto para conciliar la vida laboral y familiar. Igualmente, debería regularse la posibilidad del disfrute de la prestación económica por maternidad, reconocida en la legislación española.

Sexta: sería necesario regular si el hijo goza de un derecho legítimo de conocer su origen biológico, como sucede ya en el caso de la adopción pero no, en cambio, en el caso de donación anónima de gametos, ya que en Espańa no se permite esta opción, salvo supuestos muy excepcionales por motivos de salud para el menor, dando lugar así a una violación del derecho del menor a conocer sus orígenes tal y como reconoce el Convenio Internacional de Derechos del Niño de 1989.

En definitiva, he planteado controversias y situaciones que podrían surgir a lo largo del proceso de la maternidad subrogada. Si la ley regulase todas estas cuestiones se evitarían los efectos negativos que es posible causar con esta práctica y que son, precisamente, los que justifican su rechazo. A la vista de esta situación, las leyes tienen que cambiar para ajustarse a la nueva demanda social y para garantizar una seguridad jurídica que es derecho de todo ciudadano. Sin embargo, no solo me refiero a leyes que permitan estas prácticas de reproducción asistida, sino leyes sobre adopción, leyes sobre derechos de los matrimonios de igual sexo, leyes sobre la igualdad, etc. En definitiva, nos queda a todos un largo camino por recorrer.

\section{Agradecimientos}

El presente trabajo ha sido realizado gracias al proyecto de investigación: Responsabilidad causal de la comisión por omisión: Una dilucidación ético-jurídica de los problemas de la inacción indebida. REFERENCIA: FFI2014-53926-R. ACRÓNIMO: KONTUZ!.. WEB: kontuz.weebly.com y gracias a la Ayuda del Departamento de Educación, Universidades e Investigación del Gobierno Vasco para apoyar las actividades de grupos de investigación del sistema universitario vasco, con referencia IT581-13. 


\section{Referencias}

1. Emaldi Cirión A. Consideraciones bioéticas y jurídicas sobre la biotecnología con fines eugenésicos. Acta Bioethica 2015; 21(2): 247-257.

2. Brena Sesma I. Maternidad subrogada. Enciclopedia de Bioética y Bioderecho. Granada: Comares; 2011: 1072-1077.

3. Emaldi Cirión A. El consejo genético y sus implicaciones jurídicas. Granada: Comares; 2001: 395-407.

4. Igareda González N. La gestación por sustitución necesita un cambio legislativo en España. A propósito de la sentencia del Tribunal Supremo español no 853/2013 sobre loa gestación por sustitución. Revista de Derecho y Genoma Humano 2015; 40: 171-191.

5. Gobierno de España. Convenio para la protección de los Derechos Humanos y la dignidad del ser humano con respecto a las aplicaciones de la Biología y la Medicina (1997).

6. European Union. A comparative study on the regime of surrogacy in EU Member States. Brussels: European Union: 2013.

7. Ley Orgánica $2 / 2010$, de 3 de marzo, de salud sexual y reproductiva y de la interrupción voluntaria del embarazo. Boletín Oficial del Estado 04/03/2010; 55.

8. Farnós E. Inscripción en Espańa de la filiación derivada del acceso a la maternidad subrograda en California. Cuestiones que platea la Resolución de la DGRN de 18 de febrero de 2009. InDret, Revista para el Análisis del Derecho, Barcelona, España, enero 2010; 6-67.

9. González Camarero G. Notas sobre la resolución de la Dirección General de los Registros y del Notariado de 18 de febrero de 2009, en un caso de gestación por sustitución. Diario La Ley, 26 de agosto de 2012; 4.

10. De Barrón P. La posibilidad de inscribir en el Registro Civil español a los nacidos en el extranjero, de una madre de alquiler. Revista de Derecho y Genoma Humano 2009; 31: 29-41.

11. Gobierno de España. Decreto de 14 de noviembre de 1958, por el que se aprueba el Reglamento de Registro Civil. $B O E$ 1958; 296. Disponible en http://noticias.juridicas.com/base_datos/Privado/rrc.html

12. Ruiz Sáenz A. Gestación por sustitución: problemática jurídica de los vientres de alquiler. En Palomar A, Cantero J, (dirs.). Tratado de Derecho Sanitario, Vol. II. España: Thomson Reuters Aranzadi, Cizur Menor; 2013: 805-810.

13. Corral García E. El derecho a la reproducción humana: ¿¿debe permitirse la maternidad subrogada? Rev Der Gen H 2015; 38: 45-69.

14. García Amez, J. Maternidad subrogada llevada a cabo en el extranjero: una mirada normativa y jurisprudencial de la realidad en Espańa. Revista de Derecho y Genoma Humano 2014; 40: 147-170.

15. Paniza Fullana A. Gestación por sustitución e inscripción de la filiación en el Registro Civil español: La Sentencia del Tribunal Supremo de 6 de febrero de 2014. Revista Doctrinal Aranzadi Civil-Mercantil 2014; 1.

16. García Alguacil MJ. ¿'Incoherencia legislativa o despropósito judicial?: A propósito de la STS de 6 de febrero de 2014. Revista Doctrinal Aranzadi Civil-Mercantil 2014; 3: 80-110.

17. De Verda y Beamonte, J.R., Inscripción de hijos nacidos mediante la gestación por sustitución. A propósito de la sentencia del Juzgado de Primera Instancia no 15 de Valencia, de 15 de septiembre de 2010. Diario La Ley 2010; D-334: 1520.

18. Morgan D. Surrogacy: An introductory essay. In: Lee R, Morgan D. (eds.). Birthrights. Law and Ethics at the Beginnings of Life. London: Routhledge; 1989: 58.

Recibido: 9 de marzo de 2016

Aceptado: 25 de mayo de 2016 